\title{
Fraktal Analiz Kullanılarak Arnavutköy'ün Kentsel Yayılma Özelliklerinin Zamansal Değişiminin İncelenmesi
}

\author{
Azize UYAR¹, Derya ÖZTÜRK¹ \\ ${ }^{1}$ Ondokuz Mayıs Üniversitesi, Mühendislik Fakültesi, Harita Mühendisliği Bölümü, 55200, Samsun
}

(Alınıș / Received: 22.01.2019, Kabul / Accepted: 24.10.2019)

\begin{abstract}
Anahtar Kelimeler
Kentsel yayılma,

Fraktal boyut,

Kutu sayma yöntemi, CORINE,

CBS
\end{abstract}

\begin{abstract}
Özet: Arnavutköy, Türkiye'nin en fazla nüfusa sahip şehri olan İstanbul'un son yıllarda en çok değişim gösteren ilçeleri arasında yer almaktadır. Bu çalışmada, Arnavutköy ilçesinde kentsel büyüme deseni ve yayılmanın değișimi incelenmiștir. Arnavutköy'ün büyüme sürecinde kentsel yayılmanın ne yönde ve ne kadar değiştiğinin tespiti için fraktal analiz kullanılmıştır. Bu amaçla 1990 ve 2012 yllarına ait CORINE (Coordination of Information on the Environment) verilerinden Coğrafi Bilgi Sistemleri (CBS) ortamında kentsel alanlar elde edilmiş, kentsel alanların fraktal boyutu kutu sayma yöntemiyle hesaplanmıştır. Toplam yüzölçümü 453 km2 olan Arnavutköy'ün 1990 yılında 12,49 km2 olan kentsel alanlarının yüzölçüm değeri 2012 yılında 45,61 km2'ye ulaşmıştır. Bu yüzölçüm artışı gerçekleşirken 1990 yllında 0,9625 olan fraktal boyutun 2012 yllında 1,2789 değerine ulaşttğı tespit edilmiștir. Artan fraktal boyut değeri 1990-2012 periyodunda mekânsal kompleksliliğin, dolayısıyla kentsel yayılmanın arttığını göstermiștir.
\end{abstract}

\section{Investigation of Temporal Changes in Urban Sprawl Pattern in Arnavutköy Using Fractal Analysis}

\section{Keywords}

Urban sprawl,

Fractal dimension,

Box-counting method,

CORINE,

GIS

\begin{abstract}
Arnavutköy district is one of the most changing districts of Istanbul province which has the highest population in Turkey. In this study, the urban growth pattern and the change of sprawl were examined. The fractal analysis was used to determine the direction and amount of urban sprawl during the growth process of Arnavutköy. For this purpose, urban areas were obtained from the CORINE (Coordination of Information on the Environment) data of 1990 and 2012 in GIS environment and fractal dimension of urban areas was calculated by box-counting method. The urban areas of Arnavutköy, which has a total surface area of $453 \mathrm{~km}^{2}$, was $12.49 \mathrm{~km}^{2}$ in 1990 and reached an area of $45.61 \mathrm{~km}^{2}$ in 2012. With the increase of the urban areas, it was determined that the fractal dimension, which was 0.9625 in 1990 , reached 1.2789 in 2012 . Increased fractal dimension value showed that spatial complexity and hence urban sprawl increased in the 1990-2012 period.
\end{abstract}

\section{Giriş}

Hızlı nüfus artışı kentlerde çoğu zaman plansız büyüme ve çeşitli çevre sorunlarına yol açmaktadır. Kentler temel olarak kompakt büyüme veya kentsel yayılma formunda değişim gösterir. Her iki kentsel büyüme şeklinin kendine özgü olumlu ve olumsuz tarafları bulunmaktadır. Ancak kentsel yayılma kompakt büyümeye oranla daha fazla sosyal, ekonomik ve çevresel problemlere neden olmaktadır [1], [2].

Kentsel yayılma ile ortaya çıkan sorunların tespit edilmesi, yorumlanması ve gerekli önlemlerin alınması etkin yönetim ve planlama açısından önemlidir. $\mathrm{Bu}$ nedenle kentsel yayılmanın derecesi, nedenleri ve sonuçlarının araştırılması konusu literatürde önemli bir yer tutmaktadır. Özellikle son yıllarda teknolojik gelişmeler paralelinde, kentsel 
yayılmanın kantitatif yöntemler ile araştırılması giderek yaygınlaşmaktadır. Bu kapsamda kentsel yayılma konusunda kazandırdığı yeni bakış açılarıyla fraktal analiz dikkat çeken yöntemlerden birisi olmuştur [1], [3], [4], [5].

Bu çalışmada; Türkiye'nin en fazla göç alan ve en fazla nüfusa sahip ili olan İstanbul'un son yıllarda önemli değişimler gösteren Arnavutköy ilçesinde kentsel yayılmanın 1990-2012 periyodundaki zamansal değişimleri fraktal analiz yöntemiyle incelenmiştir.

\section{Materyal ve Metot}

\section{1. Çalışma Alanı}

Arnavutköy ilçesi (Şekil 1) İstanbul'un son yıllarda yerleşim alanı en fazla artan ilçeleri arasındadır. 2009 yılında ilçe statüsü alan Arnavutköy 261.655 kişilik nüfusa ve 38 mahalleye sahiptir [6], [7]. Arnavutköy son yıllarda kent içi ana arterler ve metrobüs hatları gibi önemli ulaşım ağlarına sahip olmuş ve yerleșim alanlarındaki artışlar ile büyük bir değişim göstermiştir.

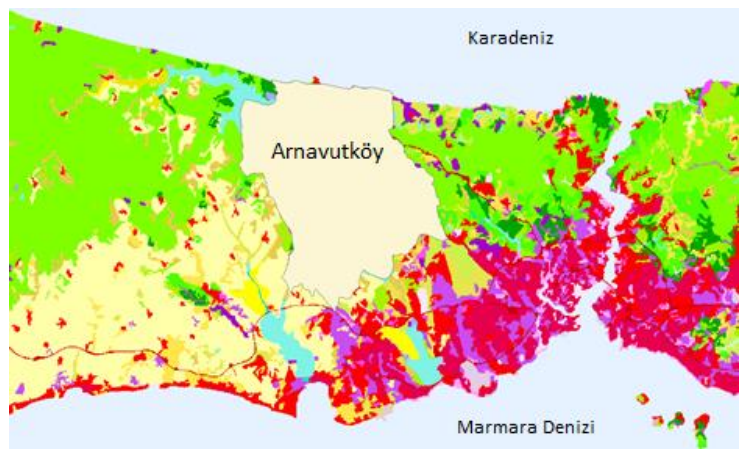

Şekil 1. Arnavutköy ilçesi

\subsection{Veri ve Metodoloji}

Arnavutköy'ün kentsel alanlarının tespiti için CORINE (Coordination of Information on the Environment) verisinden yararlanılmıştır. CORINE 1980'lerden itibaren, belirli periyotlarla Avrupa Birliği (AB) ülkelerini kapsayacak șekilde arazi örtüsü/kullanımını belirleyen bir sistemdir ve bu arazi sınıflandırma sistemi, $\mathrm{AB}$ ülkelerinin tamamına ait bir arazi örtüsü/kullanımı haritasının üretilmesi, standart bir veri tabanının oluşturulması ve çevresel politikaların belirlenmesi gibi amaçlar doğrultusunda kurulmuştur [8].

1990 ve 2012 yıllarına ait CORINE 3. düzey verilerinden (Şekil 2'de 1990 yılına ait veri gösterilmektedir) 111 (sürekli kentsel doku), 112 (süreksiz kentsel doku), 121 (sanayi, ticari alanlar), 122 (karayolu, demiryolu ve ilgili alanlar), 123 (liman alanları), 124 (havalimanları), 133 (inşaat alanları), 141 (kentsel yeșil alanlar) ve 142 (spor ve rekreasyon alanları) kodlu sınıflar birleştirilerek yapı, ulaşım, inşaat ve rekreasyon alanlarını kapsayan kentsel alanlar elde edilmiştir (Şekil 3).

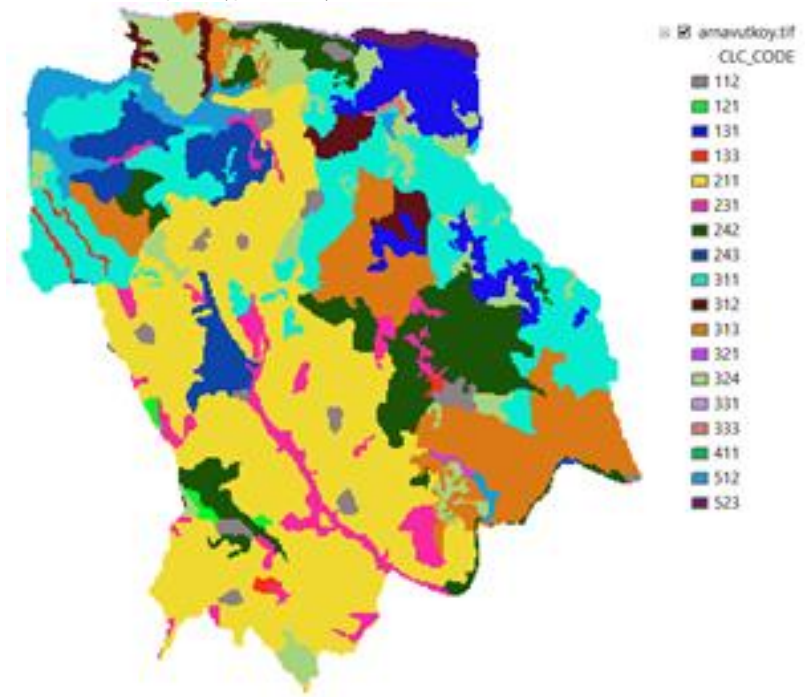

Şekil 2. Arnavutköy 1990 yılı CORINE 3. düzey verisi

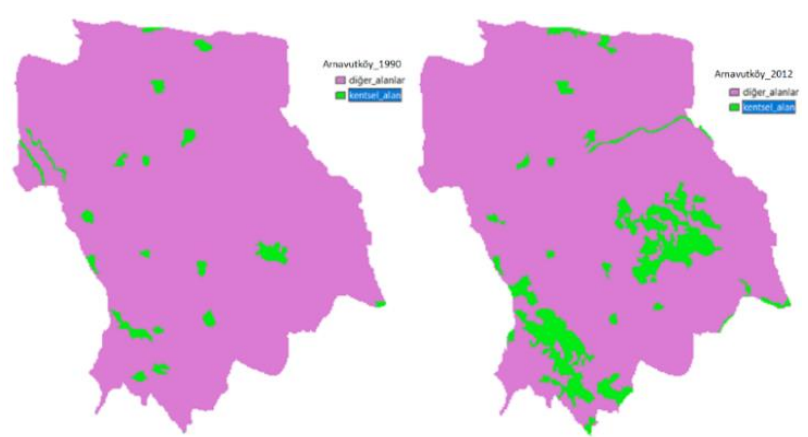

Şekil 3. 1990 ve 2012 yılları Arnavutköy kentsel alanları

Arnavutköy ilçe sınırı içerisinde kentsel alanlar 1, diğer alanlar 0 olarak kodlanarak 1990 ve 2012 yılları için ikili görüntüler oluşturulmuş (Şekil 4) ve bu ikili görüntüler kullanılarak kentsel alanların fraktal boyutu kutu sayma yöntemiyle hesaplanmıștır. Minimum kutu boyutu 5 piksel, maksimum kutu boyutu görüntünün \%40'ı olarak seçilmiş, 12 farklı kutu konumu ile fraktal boyut hesaplanmış ve ortalama fraktal boyut belirlenmiştir.
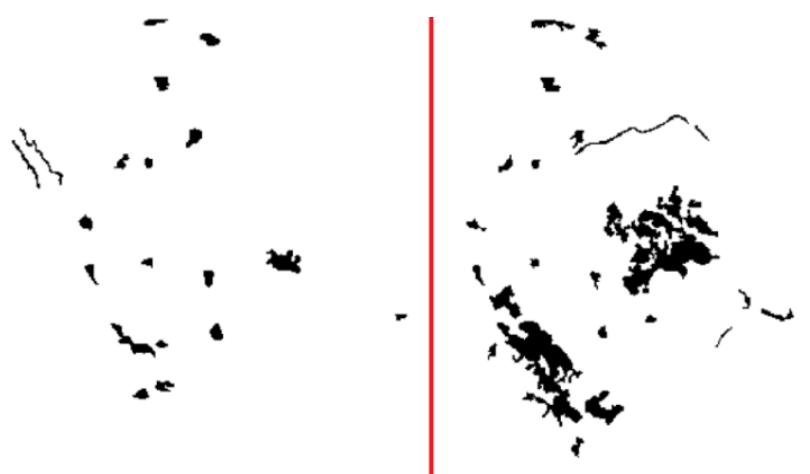

Şekil 4. 1990 ve 2012 yılları Arnavutköy kentsel alanları 
Fraktal analiz

Fraktal analiz ile nesnelerin, sistemlerin ve süreçlerin incelenmesi mümkündür. Doğadaki olayların, nesnelerin, sistemlerin veya süreçlerin temel özellikleri ve karmaşıklık seviyeleri fraktal analiz ile sayısal olarak tespit edilebilmektedir. Bu sayısal ifade fraktal boyut (D) olarak adlandırılır ve fraktal boyut değeri arttıkça nesne kompleksliliğinin arttığı şeklinde yorumlanmaktadır [9], [10], [11].

\section{Kutu Sayma Yöntemi}

Kutu sayma yöntemi basit ve uygulanabilir olduğu için en çok tercih edilen fraktal boyut hesaplama yöntemidir. $\mathrm{Bu}$ yöntemde bir görüntüdeki fraktal boyutu hesaplamak için nesne farklı büyüklüklerde grid hücreleriyle (kutu) kaplanır. Daha sonra grid büyüklükleri ile görüntünün en az bir kısmını içeren gridlerin sayısı dikkate alınarak işlem yapılır. Grid büyüklükleri ile nesneyi örten grid sayısının oranı fraktal boyutu vermektedir. Kutu sayma yöntemine göre fraktal boyut hesabı Denklem 1'de gösterilmektedir [12], [13], [14].

$$
D_{B}=\frac{\log N_{2}-\log N_{1}}{\log S_{2}-\log S_{1}}
$$

Burada; DB kutu sayma yöntemiyle hesaplanan fraktal boyutu, N kutu sayısı, S kutu boyutunu ifade etmektedir.

Mekânsal verilerin düzenlenmesi ArcGIS 10.2 yazılımı ile Coğrafi Bilgi Sistemleri (CBS) ortamında, ikili görüntülerden fraktal analiz ise ImageJ yazılımı üzerinde çalışan FracLac plugini kullanılarak gerçekleştirilmiştir. Şekil 5'te FracLac plugininin ekran görüntüsü gösterilmektedir. Burada "min size (pixels) ve "max (\% of image)" minimum ve maksimum kutu boyutu, "positions" ise kutu konum sayısı parametrelerinin belirlenmesi için kullanılmaktadır [14].

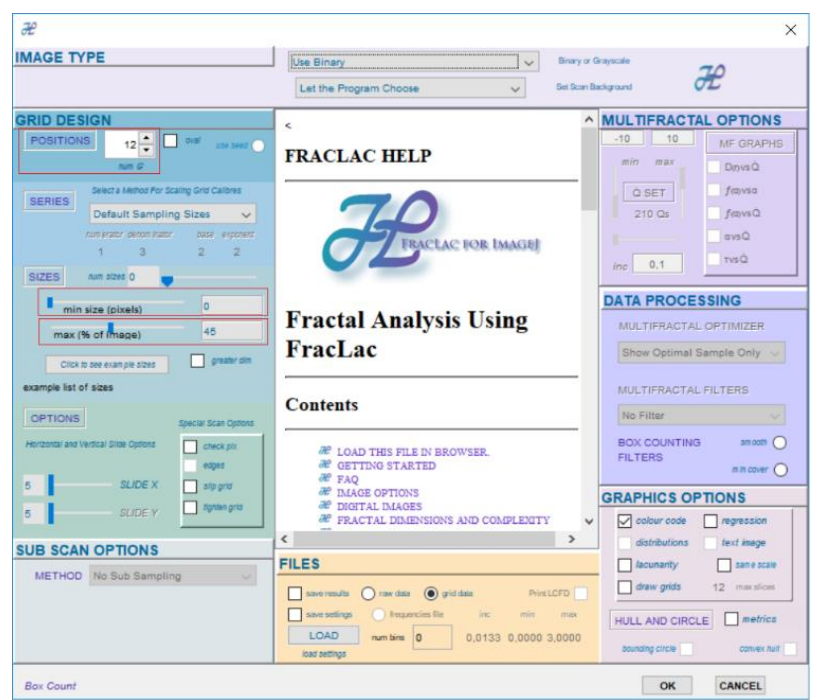

Şekil 5. FracLac plugini ekran görüntüsü

\section{Bulgular}

CORINE verisinden elde edilen bilgilerle Arnavutköy ilçesinin 1990 yılında kentsel alanının 12,49 km2 iken 2012 yılında 45,61 km2'ye ulaştığı belirlenmiştir. Kutu sayma yöntemiyle 1990 yılı için fraktal boyut 0,9625 hesaplanırken, bu değer 2012 yılında 1,2789 değerine ulaşmıştır. Fraktal boyut kompleksliğin bir ifadesi olduğundan fraktal boyuttaki bu artış Arnavutköy ilçesinde 1990-2012 yılları arasında kentsel yayılmanın ciddi oranda arttığını göstermektedir. 1990 ve 2012 yılları için fraktal boyut değerlerinin Fraclac ile hesabı Şekil 6 ve 7'de gösterilmiştir.

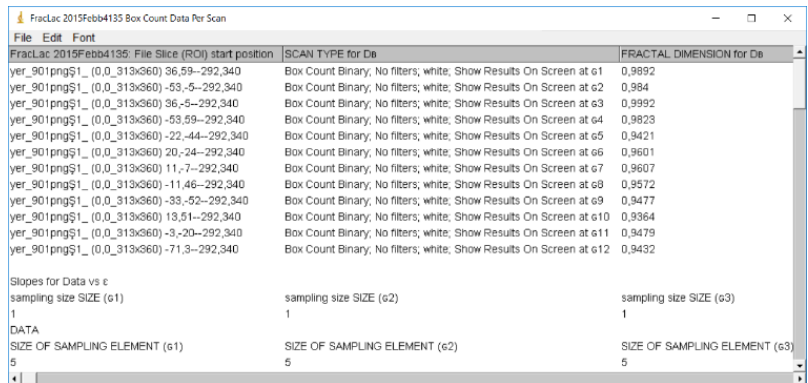

Şekil 6. 1990 yılına ait kentsel alanların fraktal boyut hesabı

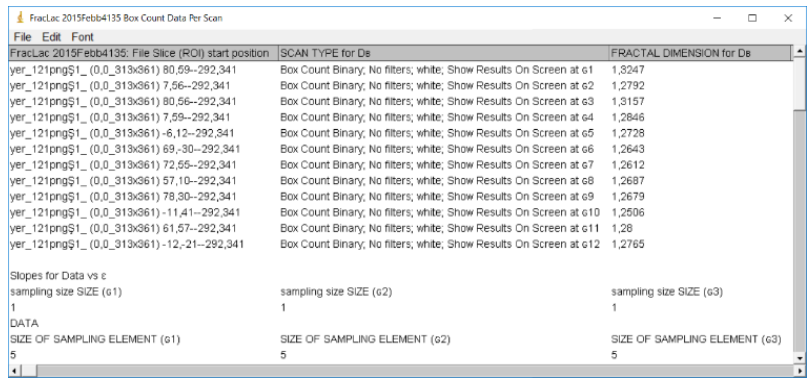

Şekil 7. FracLac plugini ekran görüntüsü

\section{Tartışma ve Sonuç}

Günümüzde hızlı nüfus artışı ve plansız büyüme, kentlerde çeşitli çevre sorunlarına neden olmaktadır. $\mathrm{Bu}$ nedenle kentsel değişimlerin izlenmesi, yorumlanması ve gerekli tedbirlerin alınması kentlerin doğru gelișimi için büyük önem taşımaktadır. Kentsel değişimlerin incelenmesi kapsamında kentsel yayılmanın derecesinin, kentsel yayılmaya neden olan faktörlerin ve kentsel yayılma sonuçlarının irdelenmesi günümüzde önemli araştırma konuları arasında yer almaktadır.

Bu çalışma kapsamında Arnavutköy ilçesinin kentsel yayılması fraktal analiz ile sayısal olarak ifade edilmiștir. Elde edilen fraktal boyutlardaki değișime göre Arnavutköy'ün 1990-2012 yılları arasında kentsel yayılma gösterdiği sonucuna varılmıştır. $\mathrm{Bu}$ sonuç doğrultusunda kentsel yayılmanın fraktal boyut ile tespit edilebileceği ve gelecekte yapılacak çalışmalarda kentsel yayılmanın fraktal boyut ile birlikte irdelenebileceği önerilmektedir. 


\section{Kaynakça}

[1] Kaya, H. S., Terzi, F., Bölen, F. 2009. Kentsel Doku İle Şehirsel Büyüme Biçimi Arasındaki İlişkinin Mekânsal Analizi: İstanbul Örneği, CBS Sempozyumu, 10-11 Aralık 2009, İzmir, 161-170.

[2] Terzi, F., Bölen, F. 2010. İstanbul'da Şehirsel Saçaklanmanın Ölçülmesi. İTÜ Dergisi, 92(2010), 166-178.

[3] Öztürk, D., 2017. Shannon Entropi ve Fraktal Analiz ile Kentsel Yayılmanın İncelenmesi: Samsun Örneği. 16. Türkiye Harita Bilimsel ve Teknik Kurultayı, 3-6 Mayıs 2017, Ankara.

[4] Akseki, H., Meşhur, M. Ç. 2013. Kentsel Yayılma Sonucu Yapılaşmaya Açllan Verimli Tarım Alanları: Konya Kenti Deneyimleri. Megaron Dergisi, 8-3(2013), 165-174.

[5] Lugaric, L., Krajcar, S., Simic, Z. 2010. Smart City Platform for Emergent Phenomena Power System Tested Simulator. IEEE Innovative Smart Grid Technologies Conference, 19-21 Ocak 2010, Zagreb, Europe. 1-7.

[6] Nüfus bilgisi. https://www.tuik.gov.tr (Erişim Tarihi: 03.10.2018).

[7] Arnavutköy Belediyesi. https://www.arnavutkoy.bel.tr/icerik/635/174 1/mahalleler.aspx (Erişim Tarihi:03.10.2018).

[8] CORINE Land Cover. https://www.eea.europa.eu/publications/COR0 -landcover (Erişim Tarihi:03.10.2018).

[9] Mikaeili, M., Memlük, Y. 2013. Ekoloji ve Çevre Açısından Kompakt Kent Kavramı ve Uygulama Örnekleri. Anadolu Doğa Bilimleri Dergisi, 42(2013), 37-50.

[10] Andronache, I., Ciobotaru, A. M. 2012. Fractal Analysis of Certain Climatic, Hydrologic and Geomorphologic Parameters within the Balta Mica of Braila Natural Park (Romania). Journal of Wetlands Biodiversity, 2(2012), 81-94.

[11] Ediz, Ö. 2003. Mimari Tasarımda Fraktal Kurguya Dayalı Üretken Bir Yaklaşım. İstanbul Teknik Üniversitesi, Fen Bilimleri Enstitüsü, Doktora Tezi, 185s, İstanbul.

[12] Wahl, B. 2016. Fractal Explorer, http://www.wahl.org/fe/HTML_version/link/F E4W/c4.htm\#hausdorff (Erişim Tarihi: 05.10.2018).

[13] Değirmenci, F. B. 2009. Fraktal Geometri ve Üretken Sistemlerle Mimari Tasarım. İstanbul Teknik Üniversitesi, Fen Bilimleri Enstitüsü Yüksek Lisans Tezi, 86s, İstanbul.

[14] FracLac Advanced User's Manual, FracLac for ImageJ-Using FracLac V2.0 for ImageJ, 2004. 